\title{
Consent and Quality of Information for Patients in Laparoscopic Surgery at the Academic Hospital Point “G” (Mali)
}

\author{
Soumaïla Keita*, Madiassa Konate, Mamadi Coulibaly, Abdoulaye Kante, Traoré Amadou, \\ Diarra Mamadou Salia, Marius Sanou, Aboubacar Sidiki Sangare, Lamine Soumare, \\ Sekou Koumare, Oumar Sacko, Brahima Dicko, D. Kanikomo, Zimogo Zié Sanogo
}

Service de Chirurgie A, CHU du point G, Bamako, Mali

Email: *keita_soumi@yahoo.fr

How to cite this paper: Keita, S., Konate, M., Coulibaly, M., Kante, A., Amadou, T., Salia, D.M., Sanou, M., Sangare, A.S., Soumare, L., Koumare, S., Sacko, O., Dicko, B., Kanikomo, D. and Sanogo, Z.Z. (2018) Consent and Quality of Information for Patients in Laparoscopic Surgery at the Academic Hospital Point “G” (Mali). Surgical Science, 9, 502-508.

https://doi.org/10.4236/ss.2018.912058

Received: November 26, 2018

Accepted: December 26, 2018

Published: December 29, 2018

Copyright $\odot 2018$ by authors and Scientific Research Publishing Inc. This work is licensed under the Creative Commons Attribution International License (CC BY 4.0).

http://creativecommons.org/licenses/by/4.0/ (C) () Open Access

\begin{abstract}
Objectives: To evaluate the quality of the information provided to patients for their consent to be operated laparoscopically in the "A" surgery service of Point "G" University Hospital in Bamako (Mali). Methodology: The study was transversal, descriptive and prospective from November 1, 2016 to December 31, 2017 (14 months). It was performed at the general and laparoscopic surgery department of the Point "G" University Hospital in Bamako. Laparoscopically operated patients in scheduled or emergency programm whom consented the study and answered the questions before and after the surgical procedure were included. Results: One hundred patients were retained. The sex ratio was 4.2 for women. The surgery was scheduled in $93 \%$ (programmed surgery) of cases versus $7 \%$ (urgent surgery). Gynecological and obstetric surgery was performed in 54\%, digestive surgery in $43 \%$ and laparoscopic exploration in $3 \%$. The information was provided by surgeons, anesthetists, fellowship and students in respectively $63 \%, 6 \%, 11 \%$ and $9 \%$. The reflection period before consenting to the act was greater or equal to 3 days in $90 \%$. The media used were found to be suitable in $62 \%$. The information was considered satisfactory preoperatively in $54 \%$ and postoperatively in $88 \%$. Patients wanted additional information on post-surgery outcomes in $21 \%$. Conclusion: The establishment of an information system and a free and informed consent form is a prerequisite for the quality of care in laparoscopic surgery.
\end{abstract}

\section{Keywords}

Laparoscopy, Information, Consent 


\section{Introduction}

Laparoscopic surgery started in Mali in 2001. It became in the surgical context of surgery " $A$ " service an alternative to the classic laparotomy for the management of many surgical diseases [1].

Despite its reputation for safety, it is very dependent on technology accompanying it and its practice remains subject to risks that are multifactorial. Patients operated by laparoscopy often have little information on the benefits, risks, existence of other therapeutic alternatives and the possibility of laparo-conversion.

The doctor must give loyal, clear and appropriate information to the person whom he examines, treats or advises about his state, the investigations and the care that he proposes to him. Throughout the illness, he must considerer the patient's personality in his explanations and ensures their understanding [2].

The patient's charter of October 6, 2008 in its article 13 in Mali, states that information provided to the patient must enable him to obtain a complete overview of all the medical and other aspects, of his condition and to take himself the decisions or to participate in decisions that may affect their well-being [3] [4]. It is the physician's responsibility to prove that he has performed this obligation.

The purpose of this work is to evaluate the quality of the information provided to patients for their consent to be operated laparoscopically in the " $\mathrm{A}$ " surgery department of the academic hospital point " $G$ " in Bamako (Mali).

\section{Methodology}

The study was transversal, descriptive and prospective from November 1, 2016 to December 31, 2017 (14 months). It was performed in the general and laparoscopic surgery department of the point "G” University Hospital in Bamako.

Laparoscopically operated patients in scheduled or emergency programm whom consented the study and answered the questions before and after the surgical procedure were included. Patients operated by conventional means or other techniques and those who did not consent were not selected.

The laparoscopic approach consisted of a consultation of anesthesia following a standard assessment of operability and a summary preparation of the patient according to the surgical context.

The information was provided by the surgeon, the doctors in training or anyone with the competence to do it. It consisted essentially of a description of the procedure, the expected benefits, the risks involved, the possibility of conversion to laparotomy and the existence of other therapeutic alternatives. Explicit informed consent was obtained from patients or their families before each intervention.

The equipment used was a laparoscopic column with instrumentation made of devices that were mostly reusable. Patient installation was dependent on the type of intervention. Anesthesia was general in type with intubation and curarization. The laparoscopic open was the rule to introduce the optical trocar with a foam-tipped mandrel. The number and position of the trocars depended on the diagnosis and the operating difficulties. 
The data collection was done from an elaborate questionnaire; the confidentiality and anonymity of the patients were respected.

\section{Results}

One hundred patients were selected according to the study criteria. The sex ratio was 4.2 for women. The age group from 30 to 39 years was the most represented with $36 \%$. Among the occupations, housewives were $59 \%$ and civil servants $11 \%$. The consent was given by the patient himself in $94 \%$ and in $6 \%$ by a legal representative. The literate patients including Koranic studies with a primary education level or above were $86 \%$. The patients came from Bamako in $84 \%$ and had consulted according to another person or had been referred in $94 \%$. The patients were operated on elective surgery in $93 \%$ versus $7 \%$ urgently. Surgical procedures were performed in a context of gynecological and obstetrical surgery in $54 \%$, digestive surgery in $43 \%$ and laparoscopic exploration in $3 \%$. The information was provided by the surgeons during the consultation in $63 \%$, the anesthetists in $6 \%$, the fellowship in $11 \%$, resident students in $9 \%$, the nurse responsible of the service in $7 \%$ and unspecified source in $4 \%$. The cumulative information provided by two or more health workers was found in $24 \%$ with a discrepancy of $3 \%$. The reflection period before consenting to the act was equal or more than 3 days in $90 \%$. The information was considered sufficient to understand the disease and the nature of the surgical procedure by $12 \%$ of patients before admission to the service. The media used for the transmission of information were considered suitable in $62 \%$, unsuitable in $38 \%$. After medical visit this information regardless of the informant's qualification was considered satisfactory in $54 \%$, acceptable in $38 \%$ and insufficient in $8 \%$. In $23 \%$ the patients wanted more information. The quality of information judged by socio-demographic characteristics is described in Table 1 . The quality of information according to the informant's qualification is described in Table 2. The information was considered satisfactory preoperatively in gynecological and obstetrical surgery in $51 \%$, in digestive surgery it was $22 \%$. The quality of the information given on the various characteristics related to the disease is summarized in Table 3. After laparoscopic surgery $21 \%$ of patients wanted more information on the results obtained and $17 \%$ judged the information received preoperatively inadequate. Before discharge, $88 \%$ of patients were generally satisfied with the quality of information on the different aspects of the disease from diagnosis to management. Table 4 summarizes the quality of information on postoperative therapeutic aspects

\section{Discussion}

In Mali there is a lack of legal bases dealing explicitly with consent in all it news aspects according to the literature of Western countries [4] [5] [6]. Despite the multitude of published works on consent, very few can be compared to this study. The realities reported by respondents in the context of laparoscopic surgery may not reflect those experienced by laparotomy patients. Moreover, the 
Table 1. Informations and socio-demographic characteristics.

\begin{tabular}{cccc}
\hline Quality of information & Satisfactory & Approximate & Insufficient \\
\hline Sociodemographic data & 48 & 29 & 18 \\
\hline Age $\geq 20$ years & 66 & 7 & 8 \\
Female & 11 & 6 & 2 \\
Male & 32 & 18 & 36 \\
Literate $\geq$ primary level & 10 & 4 & 0 \\
No literate & 8 & 0 & 3 \\
State worker & 52 & 7 & 0 \\
Housewife & 2 & 8 & 1 \\
Students & 13 & 5 & \\
Liberal worker or others & & & \\
\hline
\end{tabular}

Table 2. Informations and qualification of informant.

\begin{tabular}{ccccc}
\hline Quality of information & Satisfactory & Approximate & Insufficient & TOTAL \\
\cline { 1 - 4 } Qualification of informant & & 26 & 1 & 63 \\
\hline Surgeon & 36 & 1 & 3 & 6 \\
Anesthetist & 2 & 3 & 0 & 11 \\
Fellowship & 5 & 3 & 1 & 9 \\
Internship & 2 & 2 & 3 & 7 \\
Chief nurse & 1 & 3 & 0 & 4 \\
Unspecified & 54 & 38 & 8 & 100 \\
TOTAL & & & &
\end{tabular}

Table 3. Informations and characteristics of the disease.

\begin{tabular}{ccccc}
\hline Quality of information & Satisfactory & Approximate & Insufficient \\
\cline { 1 - 2 } Characteristics disease & & 80 & 13 & 7 \\
\hline Diagnosis & 42 & 54 & 4 \\
Paraclinical examination & $\mathbf{7 8}$ & 4 & 18 \\
Purpose and nature of the act & 40 & 58 & 2 \\
Procedure & $\mathbf{8 6}$ & 9 & 5 \\
Advantages & 25 & $\mathbf{4 3}$ & 32 \\
Risks - complications & 62 & 26 & 12 \\
Conversion of laparoscopy & 22 & 31 & 47 \\
Therapeutic alternative & 75 & 14 & 11 \\
Cost of the act & 39 & 4 & 57 \\
Hospital stay & & & \\
\hline
\end{tabular}


Table 4. Informations and post-operative aspects.

\begin{tabular}{cccc}
\hline Quality of information & Satisfactory & Approximate & Insufficient \\
\cline { 1 - 3 } Charactéristics disease & 92 & 8 & 0 \\
\hline Diagnosis & 59 & 7 & 34 \\
Paraclinical examination & 81 & 19 & 0 \\
Purpose and nature of the acts & 72 & 24 & 4 \\
Procedure & 91 & 6 & 3 \\
Advantages & 38 & 55 & 7 \\
Risks complications & 76 & 8 & 16 \\
Conversion of laparoscopy & 65 & 24 & 11 \\
Therapeutic alternative & 84 & 11 & 5 \\
Cost of the act & 94 & 2 & 4 \\
Hospital stay & & & \\
\hline
\end{tabular}

study does not include the opinion of the surgeons of the service relatively to free and informed consent. There were more women with a sex ratio of 4.2 in relation to gynecological and obstetric pathologies. The age group from 30 to 39 years was the most represented with $36 \%$. In the study of Williams et al. [7] in New Zealand, patients aged 64 were the most frequents.

Surgical indications were dominated by gynecological and obstetric pathologies in 54\%. This predominance could be explained by the expertise of the service motivating a strong solicitation in the management of adnexal pathologies (in the context of infertility), extra uterine pregnancies and intraperitoneal foreign bodies (intra-uterine device migration, textilum). Indications in digestive surgery were found in $43 \%$ with cholecystectomies, appendectomies and liver abscess surgery. These procedures are the most regularly performed in laparoscopy in our work context. The laparoscopic explorations were carried out as part of the diagnostic assessment of chronic abdominal or pelvic pain of unknown etiology but also for staging in the local evaluation of neoplastic pathologies. The patients were operated on $93 \%$ in elective surgery, which allowed them to have a reflection time equal or more than 3 days in $90 \%$ before consenting to the act.

In $12 \%$, patients stated that they had prerequisites for understanding the disease and for laparoscopic surgery before taking them into the service. This information was provided during consultations by other health professionals who motivated their referral in the service. In the study of SANOGO Z.Z [8], $97.7 \%$ of the operated patients were referred by gynecologists. It is the responsibility of the professional or the health facility to provide proof of the provision of appropriate information. For this a signed form of the patient must be archived in the medical file as a proof. It is neither sufficient nor obligatory, but essential in case of pursuit. For the traceability of the information transmitted, the media used were deemed appropriate in $62 \%$, unsuitable in $38 \%$ which reflects the application of the integrated service charter in the care of 
patients.

Patient information was provided at all levels. The characteristics related to this information varied according to the qualification and the responsibility of the informant involved in the management of the patient. Each one insisted on the aspects falling within its competence. Thus an accumulation of information was found in $24 \%$ provided by two or more professionals with a discrepancy of $3 \%$. These figures could be explained by the need to renew the information at each stage of care.

The information provided by the anesthetists was found in $6 \%$ and was sufficient for the anesthesia procedure and insufficient for the surgical procedure. That given by nurse responsible was found in $7 \%$ and focused on the modalities of hospitalization and the cost of care, without details of the procedure.

Most of the information was provided by the surgeon in 63\%, partly during his consultation but also during programming. This information was considered broadly approximate in $26 \%$ and sufficient for comprehension and consent in 36\%. The need for additional information was described in $23 \%$. Song JH et al. [9] noted in their study a need for additional information in 17\%. No problem of consent was found. In the study of Diakite et al. [10] fraud, error and violence constituted the vices of consent in respectively $57.8 \%, 14.4 \%$ and $16.9 \%$. The absence of consent defect during the study is a criterion of quality of care in relation to the emphasis placed on patient information in the service.

The quality of the information was influenced by the level of education, the living socio-economic standard and the emergency context. Requirements for completeness of information increased with the level of education and among civil servants and students. These requirements were less found in housewives and the liberal professionals, probably because of their relative fatality and also because of perioperative anxiety.

The information on the characteristics of the disease and its management was found to be mostly satisfactory on the diagnostic aspects, the purpose and nature of the act, its advantages and its cost. It was mostly insufficient as to the existence of other therapeutic alternatives, the cost of care. The information on the risks, the complications and the complementary examinations were judged mainly approximate. In the study of Brooks et al. [11], 43\% of patients had no information about complementary examinations.

Postoperatively, there is an improvement in the satisfaction about the quality of the information, except that on risks and complications.

\section{Conclusion}

Medical paternalism nowadays gives way to a medicine where the patient is an actor of his care. The establishment of an information system and a free and informed consent form is a prerequisite for the quality of care in laparoscopic surgery. 


\section{Conflicts of Interest}

The authors declare no conflicts of interest regarding the publication of this paper.

\section{References}

[1] Sanogo, Z.Z., Koumaré, S., Koïta, A.K., Soumaré, L., Sacko, O., Camara, M., Keita, S. and Camara, A. (2013) Coeliochirurgie à Bamako, bilan de 112 mois de pratique. Journal Afr. Chir. Digest, 13, 1416-1420.

[2] Code de la sante publique; N R. 4127-35.

[3] Charte du malade au Mali régie par l'Arrêté N 08-2716/MS-SG du 6 octobre 2008.

[4] Code de déontologie médicale. http://www.santé.gov.ml

[5] La loi n 86-35/AN-RM du 12 avril 1986 portant institution de l'ordre national des médecins.

[6] Le code pénal du Mali, régi par la loi Nº1-99AN-RM/DU 03 Août 1961.

[7] Williams, F.B., French, K.J. and White, D.H. (2003) Informed Consent during the Clinical Emergency of Acute Myocardial Infarction (HER0-2 Consent Substudy): A Prospective Observational Study. Lancet, 361, 918-922.

https://doi.org/10.1016/S0140-6736(03)12773-0

[8] Sanogo, Z.Z., Koïta, A.K., Keita, S., Soumare, L., Fogang, K.J.J., Sacko, O., Koumare, S., Camara, M., Camara, A., Sima, M., Goita, D., Togola, B. and Sangare, D. (2014) Apport de la néosalpingostomie colioscopique dans le traitement de l'infertilité tubaire. Journal de Coeliochirurgie, 91, 1-5.

[9] Song, J.H., Yoon, H.S., Min, B.H., Lee, J.H., Kim, Y.H., et al. (2010) Acceptance and Understanding of the Informed Consent Procedure Prior to Gastrointestinal Endoscopy by Patients: A Single-Center Experience in Korea. The Korean Journal of Internal Medicine, 25, 36-43.

[10] Diakite, D. (2010) Enquête sur le consentement éclairé et les vices de consentement aux actes et soins médicaux chez les patients au CSREF et dans les CSCOM de la commune IV. Thèse de médecine, No. 364, 69.

[11] Brooks, A.J., Hurlstone, D.P. and Fotheringham, J. (2005) Information Required to Provid Informed Consent for Endoscopy: An Observational Study of Expectation. Endoscopy, 37, 1136-1139. https://doi.org/10.1055/s-2005-870196 